\title{
Glomus Tumor in a Dog
}

\author{
Kyoko SHINYA ${ }^{1,3)}$, Kazuhiro UCHIDA ${ }^{2)}$, Kouji NOMURA ${ }^{3)}$, Kiyokazu OZAKI ${ }^{4)}$, Isao NARAMA ${ }^{4}$, and \\ Takashi UMEMURA ${ }^{1)}$ \\ 1) Department of Veterinary Pathology, Faculty of Agriculture, Tottori University, 4-101 Koyama-cho, Tottori-shi, Tottori 680, ${ }^{2)}$ Uchida \\ Animal Hospital, 84-6 Nakashohnan-cho, Kagamigahara-shi, Gifu 504, ${ }^{3)}$ Marupi Lifetech Co., Ltd., 103 Fushio-cho, Ikeda-shi, Osaka \\ 563, and ${ }^{4}$ Research Institute of Drug Safety, Setsunan University, 45-1 Nagaotohge-cho, Hirakata-shi, Osaka 573-01, Japan \\ (Received 6 May 1997/Accepted 4 June 1997)
}

ABSTRACT. A mass of glomus tumor was found on the skin of the right foreleg of a ten-year old male mongrel dog. Histologically the mass contained some vasculatures and sheet-like proliferation of epithelioid tumor cells. Some blood vessels were rimmed by the tumor cells, which had a round to ovoid nucleus and plump eosinophilic cytoplasm. Immunohistochemically, smooth muscle actin and vimentin were demonstrated in the tumor cells. By electron microscopic examination, actin-like filaments with dense bodies were observed in the cytoplasm of the tumor cells. This is the first case report of a canine glomus tumor. — KEY wORDs: canine, glomus tumor, skin tumor.

The glomus body is a specialized form of arteriovenous anastomosis controlled by sympathetic nervous system. It is concerned with temperature regulation and represents a special arteriovenous shunt $[1,2,4,7,10]$. The glomus body is composed of glomus cells which are regarded as modified smooth muscle cells. The glomus tumor is an uncommon benign tumor in human beings $[1,4,8,9,12]$. Although glomus tumors in human beings and non-human primates have been well characterized in some reports, the occurrence of this tumor has not been reported in domestic animals [7]. We encountered a canine case of glomus tumor and characterized the tumor morphologically and immunohistochemically.

A ten-year old male mongrel dog had a mass on his right medial arm. This mass was incidentally discovered at trimming. The mass had an erythematous appearance and was about $0.5 \mathrm{~mm}$ in diameter at the time of excision. The mass did not recur and metastasize for three months after the excision.

After fixation in $10 \%$ formalin, tissue from the mass was embedded in paraffin wax, cuts into $5 \mu \mathrm{m}$ sections in thickness, and stained with haematoxylin and eosin (H.E.). Other sections were used for immunohistochemical staining, and processed for the labeled streptavidin biotin (LSAB) method using an LSAB kit (DAKO, Denmark). Primary antibodies used were anti-human smooth muscle actin (DAKO, Denmark), anti-human desmin (DAKO, U.S.A.), anti-bovine S-100 protein (DAKO, U.S.A.), anti-human cytokeratin (DAKO, Denmark), and anti-human vimentin (DAKO, U.S.A.). For electron microscopic examination, formalin-fixed tissue pieces were cut into $1 \mathrm{~mm}^{3}$, and postfixed in $1 \%$ osmium tetroxide. The samples were processed routinely and embedded in epoxy resin. Ultrathin sections were cut, stained with uranyl acetate and lead citrate, and examined with an electron microscope (JEM100 CX II).

Microscopically, the mass was located in the subcutaneous tissue where numerous small blood vessels and nerve bundles were found. The main histological feature of the mass was expansive sheet-like proliferation of tumor cells (Fig. 1) which had a round to oval nucleus and plump eosinophilic cytoplasm. The mass was surrounded by a thick fibrous capsule. Many blood vessels were contained in the mass (Fig. 2), and some of them were rimmed by tumor cells. Occasionally, multinuclear giant cells, eosinophils and mast cells were prominent in the stroma.

Immunohistochemically, the tumor cells were positive for smooth-muscle actin and vimentin, and negative for desmin, cytokeratin and S-100 protein. Smooth muscle cells of the vessel walls in the mass were positive for smooth-muscle actin, vimentin and desmin. Electron microscopic examination revealed that the tumor cells had thick basement membrane and contained intracytoplasmic actin-like filaments with dense bodies, pinocytotic vesicles (Fig. 3), and a few of glycogen granules.

The results of light and electron microscopic examinations suggested either epithelioid leiomyoma or glomus tumor as differential diagnoses. Contrary to the situation with epithelial leiomyoma, however, this mass was

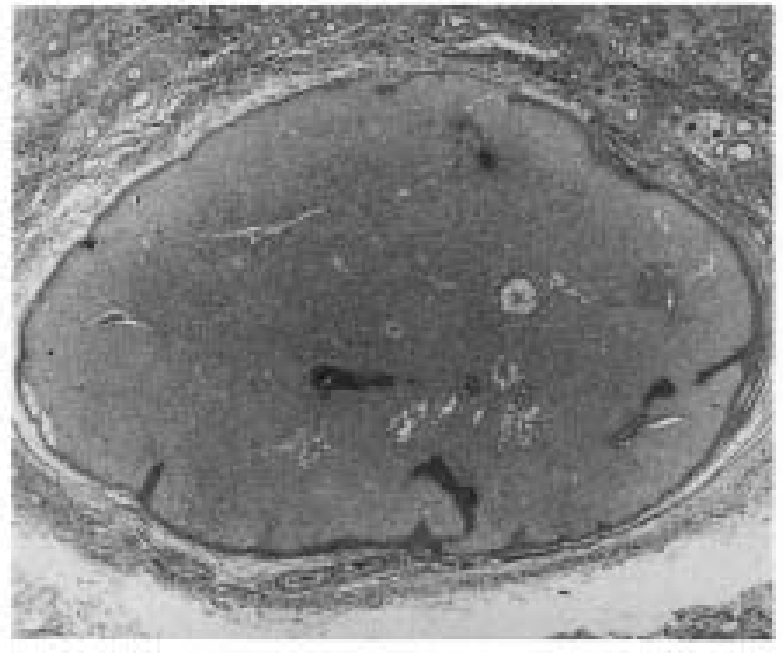

Fig. 1. Expansive growth of glomus tumor cells. The tumor tissue is encapsulated with fibrous tissue. HE. $\times 14$. 


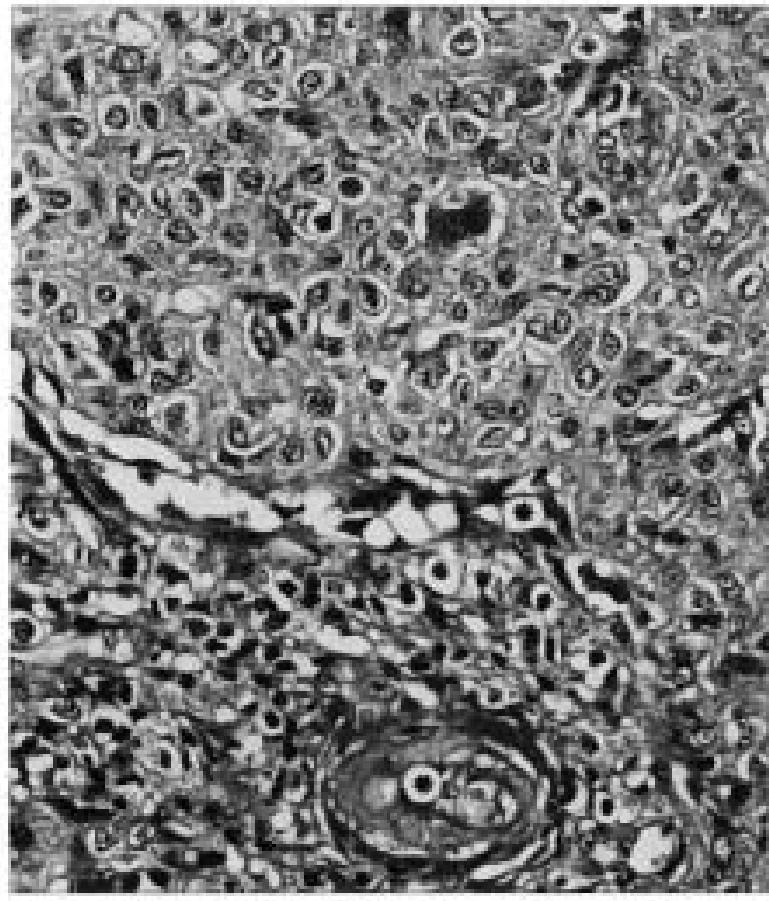

Fig. 2. Sheet-like proliferation of epithelioid tumor cells. Some vasculatures (asterisks) are in the tumor tissue. Multinuclear giant cell and perivascular infiltration of inflammatory cells are also in the tumor tissue. HE. $\times 360$.

located in subcutaneous tissue enriched with blood vessels and nerve bundles. Some blood vessels in the mass were surrounded by tumor cells, and no spindle tumor cells were in the mass [3]. These findings suggested that this mass had a strong relationship with the vasculature, and might belong to the glomus tumor class. In the literature, Macaca mulatta is the only animal that was demonstrated an occurrence of glomus tumor $[5,6]$. We describe the first case of glomus tumor in domestic animals.

In human beings, glomus tumors are uncommon benign neoplasms $[1,4,8,9,12]$. This tumor in human beings usually exists as a well-demarcated solitary mass producing severe pain, but is also seen in rare cases as multiple asymptomatic masses with some genetic association. Recent immunohistochemical examinations of human glomus tumors have shown reactivity for smooth-muscle actin and vimentin $[2,10,11]$, in contrast with absent or rarely positive reaction for desmin. Contrary to the glomus tumor of human beings, multinuclear giant cells and eosinophils were notable in this canine case. However, all other morphological and immunohistochemical properties of the tumor cells were much the same as those of human glomus tumor cells.

ACKNOWLEDGEMENTS. We would like to thank Dr. M. Tuneyoshi (Second Department of Pathology, Faculty of Medicine, Kyushu University) for valuable advice in this case, and Mrs. E. Kawahara (Tottori University) for her technical assistance.

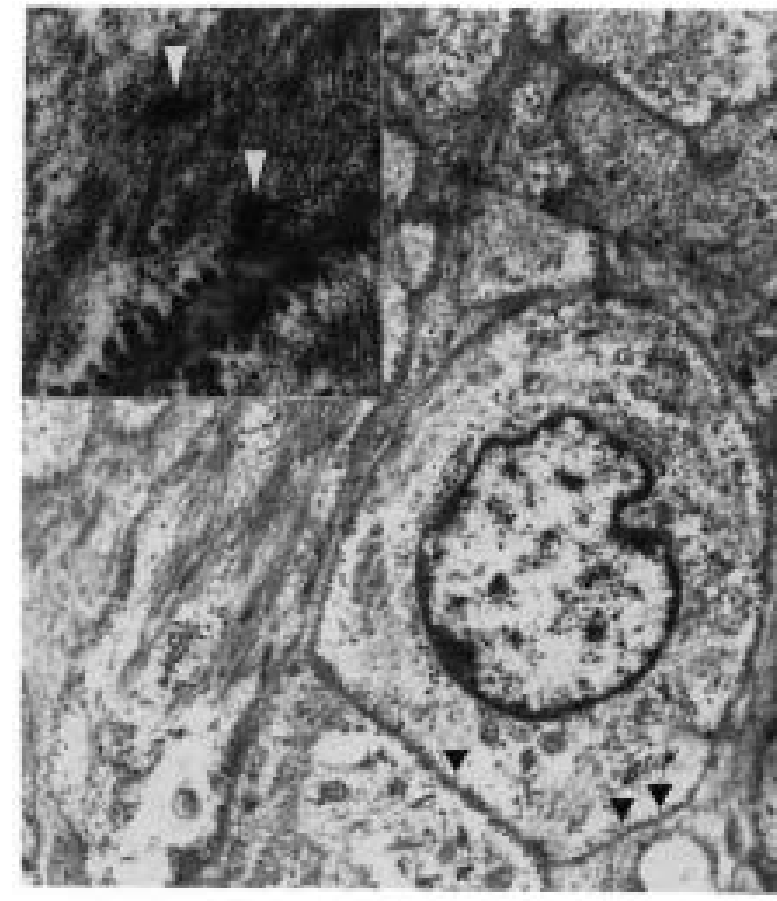

Fig. 3. The tumor cell contains actin-like filaments and numerous pinocytotic vesicles (arrow heads). Uranyl acetate and lead citrate stain. $\times 8,120$. Inset: Cytoplasmic filaments with dense bodies (white arrow heads). Uranyl acetate and lead citrate stain. $\times 26,000$.

\section{REFERENCES}

1. Ashley, D. J. B. 1990. pp. 89-92. In: Evans' Histological Appearances of Tumours, 4th ed., Churchill Livingstone, New York.

2. Dervan, P. A., Tobbia, I. N., Casey, M., O'Loughlin, J., and O’Brien, M. 1989. Histopathology 14: 483-491.

3. Enzinger, F. M. and Weiss, S. W. 1983. pp. 316-324. In: Soft Tissue Tumors. Mosby, Missouri.

4. Enzinger, F. M. and Weiss, S. W. 1995. pp. 701-733. In: Soft Tissue Tumors, 3rd ed., Mosby, Missouri.

5. Hubbard, G. B., Fanton, J. W., Harvey, R. C., and Wood, D. H. 1984. Lab. Anim. Sci. 34: 614-615.

6. Hubbard, G. B. and Wood, D. H. 1984. Vet. Pathol. 21: 609610.

7. Jubb, K. V. F., Kennedy, P. C., and Palmer, N. 1993. p. 99. In: Pathology of Domestic Animals, 4th ed., vol. 3, Academic Press, California.

8. Lever, W. F. and Schaumburg-Lever, G. 1990. pp. 700-702. In: Histopathology of the Skin, 7th ed., J. B. Lippincott Company, Pennsylvania.

9. Murphy, G. F. and Elder, D. E. 1991. pp. 207-210. In: Atlas of Tumor Pathology: Non-melanocytic Tumors of the Skin. Armed Forces Institute of Pathology, Washington, D. C.

10. Nuovo, M. A., Grimes, M. M., and Knowles, D. M. 1990. Surgical Pathol. 3: 31-45.

11. Schurch, W., Skalli, O., Lagace, R., Seemayer, T. A., and Gabbiani, G. 1990. Am. J. Pathol. 136: 771-786.

12. Tsuneyoshi, M. and Enjoji, M. 1982. Cancer 50: 1601-1607. 